REGARDS

SUR L'ECONOMIE ALLEMAND

BULLETIN ECONOMIQUE DU CIRAC
Regards sur l'économie allemande

Bulletin économique du CIRAC

93 | 2009

Varia

\title{
Enseignement : des résultats en net progrès
}

\section{Solène Hazouard}

\section{OpenEdition}

\section{Journals}

Édition électronique

URL : http://journals.openedition.org/rea/3910

DOI : 10.4000/rea.3910

ISBN : 978-2-8218-0882-9

ISSN : 1965-0787

Éditeur

CIRAC

Édition imprimée

Date de publication : 1 octobre 2009

Pagination : 35

ISSN : 1156-8992

Référence électronique

Solène Hazouard, «Enseignement : des résultats en net progrès », Regards sur l'économie allemande [En ligne], 93 | octobre 2009, mis en ligne le 01 octobre 2011, consulté le 15 septembre 2020. URL : http://journals.openedition.org/rea/3910

Ce document a été généré automatiquement le 15 septembre 2020

(C) CIRAC 


\title{
Enseignement : des résultats en net progrès
}

\author{
Solène Hazouard
}

\section{IW-Bildungsmonitor 2009 : bilan encourageant, surtout pour cinq Länder}

1 Les jeunes allemands savent mieux lire, abandonnent moins l'école, passent davantage le bac (Abitur) et s'inscrivent de plus en en plus dans les nouvelles filières de bachelor et de master. Voilà les résultats 2009 de l'enquête en matière d'enseignement IWBildungsmonitor de l'lnstitut der Deutschen Wirtschaft de Cologne, mis en place dans le cadre de l'Initiative en faveur d'une nouvelle économie de marché (Initiative Neue Soziale Marktwirtschaft). De cette évaluation portant sur 13 critères clés ressortent notamment les progrès effectués par cinq Länder depuis 2004 : le Mecklembourg avec $+11,3$ points, la Saxe $(+6,5)$, la Thuringe $(+5,6)$, la Rhénanie-Palatinat $(+5,4)$ et le Land de Brême. Affichant une hausse de 5,1 points, ce dernier doit une partie de sa réussite à l'attractivité de ses universités, qui lui permet non seulement de recruter de nombreux jeunes étudiants issus d'autres Länder, mais également d'accroître la proportion brêmoise de diplômés du supérieur.

\section{Augmentation du nombre de boursiers}

Parmi les 13 critères retenus, l'évaluation du IW-Bildungsmonitor 2009 laisse apparaître de nets progrès tels que l'optimisation du temps consacré aux études (corollaire du passage au système LMD), l'ouverture du système éducatif à l'international, une meilleure allocation des ressources ou encore l'accroissement, chez les écoliers, des compétences liées à la lecture, aux mathématiques et aux sciences naturelles. Il est par ailleurs possible d'envisager une extension future de l'analyse à l'économie, dont l'enseignement en tant que matière autonome est plébiscité par plus des trois quarts des 14-24 ans selon une enquête de la Fédération des banques allemandes, menée en 
avril dernier auprès de 753 adolescents. Autre aspect positif, relevé pour sa part par l'Office fédéral des statistiques : l'augmentation du nombre de boursiers au titre de la Loi sur la promotion de la formation (Bundesausbildungsförderungsgesetz, Bafög). Cette prestation a été versée en 2008 à près de 822000 bénéficiaires, dont 312000 écoliers et 510000 étudiants (soit respectivement $0,1 \%$ et 3,2\% de plus que l'année précédente), recevant une allocation moyenne de $321 €(+20 €)$ et $398 €(+23 €)$ par personne. (SH)

\section{INDEX}

Mots-clés : enseignement, éducation, formation, bourse, politique éducative, université, enseignement supérieur, système éducatif 